\title{
TRAÇADOS HISTÓRICOS DA PRÁTICA DO GATEBALL NO BRASIL: O CASO DE IVOTI/RS (1980-2010)
}

\author{
Josiana Ayala Ledur ${ }^{1}$ \\ Tuany Defaveri Begossi ${ }^{2}$ \\ Recebido em: 25/02/2020 \\ Aprovado em: 20/04/2020
}

\begin{abstract}
Resumo: O presente estudo objetivou investigar como transcorreu a prática do Gateball na colônia japonesa de Ivoti, no Rio Grande do Sul, entre as décadas de 1980 e 2010. Para tanto, a narrativa historiográfica foi construída apoiando-se nos pressupostos teórico-metodológicos da História Cultural. A coleta de informações ocorreu em fontes documentais, as quais foram submetidas à técnica de análise documental. Ao abordar as representações da prática corporal do Gateball na Colônia Japonesa de Ivoti, procurou-se decifrar como foram renegociadas no acenado espaço social. Assim, elencaram-se elementos culturais presentes no Gateball. É provável que a cultura deste grupo de nipo-brasileiros tenha enfrentado dificuldades nos primeiros momentos de seu estabelecimento. Contudo, tais conhecimentos não submergiram com o movimento migratório. Antes disto, este grupo, por meio do cultivo de práticas corporais, como o Gateball, procurou distinguir-se frente a diferentes grupos étnicos que compunham a sociedade em que estavam inseridos.

Palavras-chave: Gateball; Colônia Japonesa; Prática Corporal; História Cultural; História do Esporte.
\end{abstract}

\begin{abstract}
The present study aimed to investigate how the practice of Gateball took place in the Japanese colony of Ivoti, in Rio Grande do Sul, between the decades of 1980 and 2010. For that, the historiographical narrative was built based on the theoretical and methodological assumptions of Cultural History. The collection of information occurred in documentary sources, which were submitted to the technique of documentary analysis. In approaching the representations of the corporal practice of Gateball in the Japanese Colony of Ivoti, it was tried to decipher how they were renegotiated in the accented social space. Thus, cultural elements were present in the Gateball. It is probable that the culture of this group of JapaneseBrazilians faced difficulties in the first moments of their establishment. However, such knowledge did not submerge with the migratory movement. Before this, this group, through the cultivation of corporal practices, as the Gateball, tried to distinguish itself before different ethnic groups that comprised the society in which they were inserted.
\end{abstract}

\footnotetext{
${ }^{1}$ Doutoranda em Ciências do Movimento Humano pela Universidade Federal do Rio Grande do Sul (UFRGS). Integrante do grupo de pesquisa Núcleo de Estudos em História e Memória do Esporte e da Educação Física (NEHME) da UFRGS/CNPq, do Observatório do Esporte Paralímpico/UFRGS e do Centro de Memória do Esporte (CEME/UFRGS). E-mail: josiled@ hotmail.com. ORCID: https://orcid.org/0000-0002-7981-1097.

2 Doutoranda em Ciências do Movimento Humano pela Universidade Federal do Rio Grande do Sul (UFRGS). Integrante do grupo de pesquisa Núcleo de Estudos em História e Memória do Esporte e da Educação Física (NEHME) da UFRGS/CNPq, do Observatório do Esporte Paralímpico/UFRGS e do Centro de Memória do Esporte (CEME/UFRGS). E-mail: tuany_begossi@hotmail.com. ORCID: https://orcid.org/0000-0002-2596$\underline{5963 .}$.
} 
Keywords: Gateball; Japanese Ivoti Colony; Corporal Practice; Cultural History; History of Sport.

Resumen: Este estudio tuvo como objetivo investigar cómo se llevó a cabo la práctica de Gateball en la colonia japonesa de Ivoti, en Rio Grande do Sul, entre los años 80 y 2010. Para esto, la narrativa historiográfica se construyó a partir de los supuestos teóricos y metodológicos de la Historia Cultural. La información se recopiló de fuentes documentales, que se presentaron a la técnica de análisis de documentos. Al acercarnos a las representaciones de la práctica corporal de Gateball en la colonia japonesa de Ivoti, tratamos de descifrar cómo se renegociaron en el marcado espacio social. Así, se enumeran elementos culturales presentes en el Gateball. Es probable que la cultura de este grupo de japonesesbrasileños enfrentara dificultades en los primeros momentos de su establecimiento. Antes de esto, este grupo, a través del cultivo de prácticas corporales, como Gateball, buscó distinguirse frente a los diferentes grupos étnicos que formaban la sociedad en la que estaban insertos.

Palabras clave: Gateball, Colonia Japonesa de Ivoti, Práctica Corporal; Historia Cultural, Historia del Deporte.

\section{Introdução}

No sul do Brasil, o desenvolvimento de diversas práticas corporais ${ }^{3}$ esteve relacionado ao processo de associativismo esportivo ${ }^{4}$, conformado por imigrantes e descendentes de distintas nacionalidades, que se estabeleceram no país entre os séculos XIX e XX. Neste cenário, grupos étnicos, tais como os alemães, portugueses, italianos e japoneses criaram espaços - clubes e associações - com o intuito de preservar seus costumes por meio de práticas culturais e esportivas, as quais possibilitavam, além da socialização e do lazer, a demarcação de diferenciações identitárias. As pesquisas de Mazo (2003), Silva (2011; 2015), Pereira (2016), Assmann (2015; 2019) e Ledur (2017), além de outros estudos regionais no âmbito da História do Esporte, apresentam evidências históricas das práticas corporais dos referidos grupos étnicos, no estado do Rio Grande do Sul.

No que diz respeito à imigração japonesa, há evidências de que os japoneses e seus descendentes atuaram de forma mais expressiva na difusão das artes marciais (NUNES, 2011; FROSI, 2012; MAZO et al., 2019). Especificamente no estado Rio Grande do Sul, a atuação de professores de karate-do e judô em clubes e academias militares, principalmente durante as décadas de 1950 a 1980, reforça este entendimento. Todavia, para além das artes marciais, há

\footnotetext{
${ }^{3}$ As práticas corporais, segundo Silva (2014), podem ser compreendidas como fenômenos que se mostram, prioritariamente, ao nível corporal, constituindo-se em manifestações culturais, tais como os jogos, as danças, as ginásticas, os esportes, as artes marciais, as acrobacias, entre outras.

${ }^{4} \mathrm{O}$ fenômeno do associativismo esportivo designa formas de organização esportiva, como clubes, sociedades, associações, agremiações, ligas, comitês, entre outras (MAZO, 2003).
} 
uma gama de outras práticas corporais com ascendência japonesa que vem sendo cultivadas nas comunidades, tal como ocorre com o Gateball $^{5}$, foco deste estudo.

A explanação sobre o jogo de Gateball na colônia japonesa de Ivoti/RS busca reforçar a presença de "representações" culturais estabelecidos desde o início da imigração deste grupo social para o Rio Grande do Sul. Este processo tem como data oficial o dia 20 de agosto de 1956 (GAUDIOSO, 2011). A referida data marca a chegada de imigrantes japoneses ao estado para trabalhar, principalmente, em atividades ligadas a agricultura.

O presente estudo busca trazer uma versão histórica sobre o desenvolvimento do Gateball em Ivoti/RS. Ressaltamos que não temos a pretensão de trazer a palavra final sobre o desenvolvimento da mencionada prática corporal, mas sim, de contribuir para a ampliação da tímida produção científica direcionada a esta temática. Tal assertiva apoia-se em um levantamento bibliográfico que buscou identificar estudos que tenham se dedicado a analisar o perfil de atividades praticadas em comunidades nipo-brasileiras e que sustentam o Gateball enquanto atividade física (KANASHIRO; YASSUDA, 2011).

A literatura identificada apresenta-se a partir de dois eixos de análise. Um aloca-se, basicamente, na perspectiva das investigações da área da saúde, tais como da Psicologia. Neste sentido, estudos como os de Traphagan (1998) e Veloso (2010) têm dedicado atenção ao Gateball e às percepções e motivações de seus praticantes. Já as investigações como as de Dilly e Gevehr (2014), ao focar na colônia japonesa como um lugar de memória, identidade étnica e educação patrimonial de comunidade nipônica, apresentam o Gateball como um de seus aspectos culturais e sociais. Neste mesmo caminho, destaca-se o estudo de Ledur (2017) que, a partir de uma perspectiva sociocultural de análise, buscou compreender como as práticas corporais de ascendência japonesa, dentre estas o Gateball, foram desenvolvidas na Colônia Japonesa de Ivoti, no Rio Grande do Sul. Vale a ressalva de que a mencionada Colônia possui uma relevante representatividade no que se refere à identidade nipônica no Brasil.

Assim sendo, os estudos regionais que tratam de Colônias Japonesas específicas apresentam contribuições ímpares para a compreensão do cenário de desenvolvimento mais

\footnotetext{
${ }^{5} \mathrm{O}$ Gateball é um jogo semelhante ao cricket, disputado entre duas equipes, sendo cada uma composta por cinco integrantes. A competição constitui-se em passar uma bola, com a utilização de um taco, por uma sucessão de três arcos arranjados em distintas disposições em um campo retangular. A duração de cada partida é de 30 minutos, em um total de quatro jogos. A finalidade da equipe é marcar o maior número de pontos. A prática de Gateball demanda empenho físico de intensidade moderada, espírito de equipe, coordenação motora e flexibilidade; ao mesmo tempo, recruta atenção e planejamento estratégico (KANASHIRO; YASSUDA, 2011).

${ }^{6}$ Representações são presentificações de uma ausência, onde representante e representado guardam entre si relações de aproximação e distanciamento (PESAVENTO, 2006, p. 49).
} 
geral deste grupo étnico no país. Segundo Machado (2017, p. 307-308), “o real papel desses estudos é iluminar os contextos mais amplos dos quais foram parte [...]”. Ainda, tal viés de investigação também se torna relevante por possibilitar a realização de pesquisas comparativas entre distintos panoramas históricos e socioculturais.

Nesta direção, a pesquisadora japonesa Kanamoto (2007, p. 49), por exemplo, ao apresentar o dia a dia dos idosos nikkei ${ }^{7}$, em São Paulo, relatou que muitos jogam Gateball diariamente. Esta prática, inclusive, conta com torneios específicos nos eventos realizados para o intercâmbio entre os Clubes de Anciões, organizados pela Federação dos Clubes NipoBrasileiros de Anciões (Burajiru Nikkei Rôjin Kurabu Rengôkai - Rôkuren). Esta Federação foi fundada em São Paulo, no ano de 1975 (IZUMI, 2010). Ainda no estado de São Paulo, Veloso (2010) relatou a prática do Gateball por idosos no município de Guararapes (SP), nos treinamentos oferecidos por um clube japonês. Assim, é possível sublinhar que, dentre as características do Gateball, está a abrangência de um significativo contingente de praticantes idosos nas colônias do país (SUZUKI; MIRANDA, 2008; SILVA, 2012).

No estado de Santa Catarina, por sua vez, Uemura (2013) evidenciou a presença do Gateball no Núcleo Celso Ramos, fundado no município de Curitibanos (SC), no ano de 1964. Destacamos que, tanto no contexto do estado de Santa Catarina como no do Rio Grande do Sul, tem-se a presença da Associação de Assistência Nipo-brasileira do Sul (ENKYOSUL). Esta entidade foi fundada em 1969 e consiste em uma das de maior representatividade dos nipo-brasileiros nestes estados. Desde o seu aparelhamento, a ENKYOSUL desenvolve um trabalho voltado a conservar os valores culturais legados pelos antepassados, conformando-se, ainda, enquanto um espaço que oportuniza práticas corporais com fins recreativos, gerando integração entre os imigrantes japoneses e seus descendentes.

Para além da ENKYOSUL, no estado do Rio Grande do Sul, evidenciamos a presença da Associação Esportiva Recreativa da Colônia Japonesa Itapuã (ASERJI). Localizada na sede campestre desta colônia, em Viamão, a entidade foi criada em 29 de fevereiro de 1988 (EMPRESAS DO BRASIL, 2015). Segundo Ledur (2017), muitos dos moradores da colônia são idosos e praticam o Gateball na sede da ASERJI, além de também participarem de campeonatos em nível estadual e interestadual.

Na Colônia Japonesa de Ivoti/RS, por sua vez, evidenciamos a presença da Associação Cultural e Esportiva Nipo-Brasileira de Ivoti (ACENB), cujo intuito é cultivar os aspectos culturais e sociais e representar todo o grupo diante da sociedade. Constituída no ano de 1981,

7 O termo Nikkei é empregado para designar os descendentes de japoneses na América. Foi adotado, oficialmente, na Convenção Pan-americana Nikkei de 1985, em São Paulo. 
a ACENB está atrelada à ENKYOSUL e ocupa um espaço que antes se chamava somente de Clube de Japoneses (ASSOCIAÇÃO CULTURAL..., 2016). Deste modo, tais entidades representativas se dedicam a preservar e divulgar distintas práticas sociais, tradições, hábitos familiares e o próprio fazer dos costumes deste grupo étnico, os quais, são conservados, modernizados e (re)passados de geração em geração (CANDAU, 2012). A composição da identidade desse grupo, portanto, perpassa a sua ascendência étnica, abrigando-se também na memória e no constante (re)vivenciar de costumes e práticas (DILLY; GEVEHR, 2014).

Para construção do presente estudo, o contato com tais entidades tornou-se fundamental. Na ENKYOSUL foi possível consultar fontes documentais, tais como atas, diários oficiais e jornais informativos que circulam entre os associados. As informações obtidas a partir dos documentos acessados revelaram que as práticas corporais aparelhadas pela entidade contemplam e congregam, em diferentes circunstâncias, os habitantes das colônias de Ivoti, Itati e Itapuã, tal como os campeonatos de Gateball e o Undokai. Tais eventos evidenciam que as práticas corporais realizadas pelo grupo nipo-brasileiro destas colônias não ocorrem exclusivamente em uma esfera local. Ao buscar, de modo particular, indícios sobre as práticas corporais desenvolvidas na colônia de Ivoti/RS, foco da presente investigação, percebeu-se que, no tempo presente, práticas nipônicas não tão conhecidas pelos brasileiros, ao menos não com a alcunha original, consistiam em algumas das que foram conservadas, tais como o Judô, Odori ${ }^{8}$ Sumô, Undokai ${ }^{9}$ e Gateball.

Diante deste panorama, o presente estudo objetivou investigar como transcorreu a prática do Gateball na colônia japonesa de Ivoti, no Rio Grande do Sul, entre as décadas de 1980 e 2010. O recorte temporal que aponta o momento inicial deste estudo corresponde à organização da primeira associação voltada ao desenvolvimento das práticas corporais na colônia japonesa de Ivoti, em 1981, pela ação da Associação Cultural e Esportiva NipoBrasileira (ACENB). A demarcação final do período estudado, por sua vez, está atrelada à década de 2010, quando foi concebido o Memorial da Colônia Japonesa de Ivoti, instalado no ano de 2011, episódio que baliza a ocasião em que esta colônia passa a ter sua cultura e folclore divulgados em condições mais perceptíveis.

Para contemplar o objetivo apontado, esta investigação está sustentada pelos pressupostos teórico-metodológicos da História Cultural, visto que esta nos permite ponderar que a própria existência do indivíduo figura como um modo de produzir cultura por meio de

8 Odori refere-se às danças tradicionais japonesas, que são práticas corporais fundamentadas, em grande parte, por culturas populares e religiosas (LEDUR, 2017).

9 O termo Undokai significa 'encontro esportivo', ou, ainda, 'gincana esportiva familiar' (ENKYOSUL, 2012). 
seus discursos orais e corpóreos, valendo-se destes para atribuir sentido e aclamar o mundo (CHARTIER, 2000; BURKE, 2008; PESAVENTO, 2008). De modo pontual, para a construção da presente narrativa historiográfica foram coletadas informações em fontes documentais, a saber: Atlas do Esporte no Brasil, jornais, livros, revistas e informativos da ENKYOSUL. Ainda foram coletados informativos, cartazes de divulgação de eventos, como os realizados pela ACENB na Colônia Japonesa de Ivoti e pela ENKYOSUL. Além disso, buscaram-se fotografias da prática corporal em questão, sendo apresentada apenas uma imagem do Gateball. Tais materiais de pesquisa foram submetidos à técnica de análise documental (PIMENTEL, 2001).

Esta primeira seção buscou apresentar exposições introdutórias sobre a temática. Na sequência, a seção "Elementos histórico-culturais nipônicos presentes no Gateball do Brasill", aborda a conformação histórica desta prática cultural e esportiva cunhada no Japão, no final da década de 1940, e trazida ao Brasil 30 anos mais tarde. Na terceira seção "Representações da prática corporal do Gateball na Colônia Japonesa de Ivoti” são abordadas as possíveis renegociações das representações construídas em torno deste esporte no espaço social assinalado. Por fim, apresenta-se a quarta seção, Considerações Finais, e, após, segue a lista de Referências.

\section{Elementos histórico-culturais nipônicos presentes no Gateball do Brasil}

As primeiras manifestações do Gateball, esporte cunhado por Eiji Suzuki, emergiram em 1947, depois do fim da Segunda Guerra Mundial, na cidade de Memuro, na Ilha de Hokkaido, no Japão. Em um período inicial, esta prática, que se assemelha ao clássico jogo inglês Cricket, estaria voltada a promoção de uma atividade em que as crianças pudessem deleitar-se com brincadeiras divertidas que extraíssem o foco dos abalos suportados pela ruína na guerra. Emergia, então, o Gateball que, chamado pelos japoneses por "getoboru”, poderia ser praticado sem muito aparelhamento e em ambientes físicos sem muito espaço, adaptandose à realidade territorial do Japão, onde há escassa área e ampla população (UCGB, 2014).

A despeito disso, por ser uma prática simples, aos poucos se tornou uma atividade de lazer, notadamente para pessoas idosas permanecendo, assim, associada a uma das representações mais difundidas a respeito da velhice no Japão (TRAPHAGAN, 1998). Em fins dos anos 1980, o Gateball começou a ser difundido na ilha de Kyushu e, rapidamente, alastrou-se por todo o Japão. Esta afirmativa funda-se na repercussão obtida por esta prática em 1986. 
No ano em questão, a rede de televisão estatal japonesa, Nippon Hōsō Kyōkai (NHK) expôs, de modo exclusivo, uma série analisada em nove partes a propósito do Gateball. Os episódios abordavam as normas do jogo e as instruções sobre técnicas, métodos e táticas. Acompanhando esta série de televisão, também foi disponibilizada uma revista que as pessoas poderiam aproveitar para seguir a série de forma progressiva e analisar as informações proporcionadas por cada epidósio. De forma ilustrativa, a capa da revista mostrava uma mulher, em torno dos vinte anos, jogando Gateball junto com uma adolescente, um homem de meia-idade, uma mulher de meia-idade e um homem com idade mais avançada (TRAPHAGAN, 1998). Esta ilustração trazia a representação do Gateball como uma prática destinada a homens e mulheres de diferentes faixas etárias.

Em relação aos materiais demandados para o Gateball, estão: tacos, bolas e arcos. Quanto ao espaço físico necessário, normalmente, pode ser praticado tanto em quadras de terra batida, como no gramado. As medidas oficiais da quadra abarcam 20 a 25 metros de comprimento, por 15 a 20 metros de largura. É jogado por dois times, vermelho e branco, com cinco jogadores em cada equipe. Assim, os jogadores têm bolas numeradas correspondentes a sua ordem de jogo - vermelhas são ímpares e brancas são pares. O escopo do jogo é rebater as bolas, fazendo com que elas atravessem os três gates (ou arcos) e atinjam o goal pole (pino localizado no centro da quadra). Cada arco vale um ponto e o pino central vale dois. Vence a equipe que assinalar mais pontos ao longo dos trinta minutos de jogo (CANTARINO FILHO; MIURA, 2010). É permitido atirar as bolas adversárias para fora do campo, atrasando as jogadas do outro time (SILVA, 2012).

Após a regulamentação, o Gateball se expandiu para outros países, incluindo a China e Brasil (UCGB, 2014). Estimativas do ano de 2005 assinalavam que 20 milhões de pessoas praticavam o esporte no mundo, sendo que a metade estava na China, seguida pelo Japão, com cinco milhões de praticantes (ALVES; POCAIA, 2005). Vale ressaltar que, no ano de 1984, houve a fundação da União Japonesa de Gateball e, no ano seguinte, em 1985, com a participação do Brasil, foi fundada a União Mundial de Gateball (WGU) (CANTARINO FILHO; MIURA, 2010).

Em território brasileiro, o Gateball passou a ser desenvolvido em associações cunhadas por imigrantes japoneses, a partir da década de 1970. A iniciativa partiu do imigrante Matsumi Kuroki que, ao visitar o Japão teve a oportunidade de assistir a um jogo de Gateball, em novembro de 1978. A partida lhe despertou grande interesse e, após tomar conhecimento a respeito das regras e determinados aspectos técnicos, teve a ideia de introduzir esta atividade no Brasil. Apesar disso, ao averiguar que os equipamentos eram 
pesados e de volume abundante, visto que abarcava o uso de bolas, arcos, tacos e pinos, concluiu que importá-los do Japão seria praticamente inviável. Deste modo, naquela ocasião, trouxe somente o regulamento editado pela Associação de Gateball da província de Miyazaki.

Em vias de resolver a demanda dos materiais, Kuroki realizou uma busca e, em 1979, localizou uma indústria que se dispôs a produzir tacos e bolas. Tal circunstância viabilizou a concretização do primeiro jogo em equipe, disputado em 17 de julho de 1979, nas dependências da Associação de Jovens de Fukuhaku (Suzano) de São Paulo. Dois anos depois, em 1981, moradores da colônia de Fukuhaku, e de outras colônias, como Itapeti, conheceram o esporte e começaram a participar de treinamentos, tendo o livro de regulamentos trazido do Japão como base. Em 11 de setembro do mesmo ano, foi realizado, pela primeira vez no Brasil, o $1^{\circ}$ Torneio de Gateball, promovido pelo clube de anciões Hakuju-kai de Itapeti (CANTARINO FILHO; MIURA, 2010).

A prática do Gateball apresentou prosseguimento no ano de 1982, obtendo um número considerável de adeptos. Neste mesmo ano, ocorreu a construção do primeiro campo destinado à prática específica da modalidade, em São Paulo (CANTARINO FILHO; MIURA, 2010). Devido a esse desenvolvimento, tornou-se imprescindível cunhar um órgão coordenador, o qual começou a ser articulado em reuniões, por meio dos representantes dos clubes de anciões. Assim, ainda no ano de 1982, no mês de julho, conforme conclui Silva (2012): "mais de 200 pessoas reuniram-se na Associação da Colônia de Itapeti, onde foi celebrado o $1^{\circ}$ Encontro de Clubes de Gateball do Brasil”. Desta reunião, aconteceu o estabelecimento da Associação de Gateball do Brasil, com a finalidade de coordenar e propalar esta modalidade esportiva (GATEBALL..., 25 dez. 2013).

No tempo presente, existem sedes regionais responsáveis pelo esporte em, ao menos, oito estados: São Paulo, Rio de Janeiro, Mato Grosso do Sul, Goiânia, Bahia, Recife, Paraná e Rio Grande do Sul (UCGB, 2014). Em Cascavel, no Paraná, por exemplo, estima-se que a introdução do Gateball tenha principiado na década de 1980. De acordo com Silva (2012), esta prática era realizada na cidade há mais de 20 anos, congregando as pessoas todos os finais de semana, em sua maioria de descendência nipônica, na Associação Cultural e Esportiva de Cascavel (ACEC). No ao de 2012, esta entidade sediou o Campeonato do Oeste do Paraná da modalidade. O torneio, já clássico na região, contemplava no ano mencionado, sua $134^{\mathrm{a}}$ edição e contou com o comparecimento de equipes de seis cidades.

A equipe cascavelense havia conquistado um dos títulos mais respeitáveis do Gateball em 2000: o Campeonato Brasileiro. Este certame nacional foi disputado em dois dias, agrupando cerca de 230 equipes, que competiram no formato de mata-mata. A equipe de 
Cascavel não perdeu nenhuma partida e o resultado foi publicado até no Japão. A cidade ainda havia sido vice-campeã do evento em 2004. Um ano antes, Cascavel alcançou o posto de campeã paranaense de Gateball. A equipe trazia experiência também de jogos em países como a Argentina, onde disputou o Campeonato Sul-Americano da modalidade. No ano de 2012, estimava-se que Cascavel contava com mais de 30 praticantes de Gateball. As idades da equipe da ACEC variavam bastante, com uma diferença de 63 anos. O esportista mais jovem da equipe tinha 27 anos de idade e o mais velho, 90 anos. Ainda que houvesse ocasiões de treino em comum, cada um encontrava espaço para competir por meio de categorias (SILVA, 2012).

O Campeonato Brasileiro de Gateball ocorre, tradicionalmente, no mês de abril, sendo que, ao longo do ano, são realizadas as etapas regionais, assim como outras competições da modalidade (CANTARINO FILHO; MIURA, 2010). Entretanto, para além do caráter de disputa, os autores ressaltam o espírito de confraternização que perpassa os campeonatos de Gateball, configurando momentos que contribuem para a preservação das práticas culturais japonesas. Tem-se, assim, que a prática do Gateball expressava representações integradoras da vida social, arquitetadas por comunidades nipônicas, no Brasil, para sustentar a coesão dos grupos. Tal conexão coletiva por meio das representações da prática do Gateball também pode ser identificada no contexto do estado brasileiro do Rio Grande do Sul, com destaque para Ivoti que, conforme Dhein (2012) representa o município sul-rio-grandense com o maior número de famílias nipo-brasileiras.

\section{Representações da prática esportiva do Gateball em Ivoti}

Indícios apontam que o Gateball, no Rio Grande do Sul, fez parte da conjuntura da capital Porto Alegre. A pesquisa realizada por Almeida (2003), a partir de um enfoque etnográfico a respeito de grupos urbanos que aproveitavam o espaço para desenvolverem as mais variadas práticas de lazer, demonstrou que o Gateball era praticado no Parque Farroupilha, também conhecido como "Parque da Redenção". O grupo de Gateball em questão era composto por imigrantes japoneses que se reuniam semanalmente para praticar o jogo, o qual acontecia mediante uma comunicação feita exclusivamente em língua japonesa.

A faixa etária dos indivíduos variava entre 72 e 89 anos. A relação destes imigrantes com o jogo decompunha-se em ocasiões de ludicidade e de competição, representadas pela participação do grupo em campeonatos de Gateball que agrupavam pessoas advindas de múltiplos locais do Rio Grande do Sul. Afora os jogos em si, tais encontros abarcavam 
apresentações culturais japonesas, além de comidas típicas e artesanato. Isto é, para além do jogo, existia uma organização de pessoas que representavam a colônia japonesa no Rio Grande do Sul, congregando-se para avigorar a identidade japonesa por meio desta prática (ALMEIDA, 2003).

Perante este panorama, a prática do Gateball na Colônia Japonesa de Ivoti, no Rio Grande do Sul, esteve vinculada à ACENB. Na década de 1990, a concretização desta modalidade foi propalada no Jornal Livre Expressão, a partir de uma alusão à ACENB. Destacava-se que a entidade sustentava acoplada à sede, uma cancha de Gateball utilizada, especialmente, aos domingos à tarde, por idosos da comunidade ${ }^{10}$, que lá se encontravam para o lazer e diversão (COLÔNIA JAPONESA..., 17 jan. 1995). Paralelamente a estes fins, o caráter competitivo fazia-se presente na rotina dos idosos, refletindo na conjuntura de campeonatos, tal como o disputado na cidade de Campinas, São Paulo, no ano de 1996. O referido evento congregou 205 equipes de todos os estados brasileiros. Os representantes da Colônia Japonesa de Ivoti foram Masako Neshiba, Hisako Miyabe, Takeso Miyabe, Rimiko Sato, Jujiro Hikano e Sumaco Hayashi (COLÔNIA JAPONESA..., $1^{\circ}$ maio, 1996).

Na década seguinte, esta atividade, com o propósito de lazer e de sociabilidade, seguiu sendo desenvolvida na quadra de Gateball da ACENB. Os encontros se desenvolviam congregando praticantes distribuídos entre idosos e crianças, uniformizados, quase invariavelmente, com roupas e chapéus brancos, e divididos por duas equipes, tal como é imprescindível para efetivar-se a partida (IWASAKI, 2008). A autora, ao produzir uma reportagem ao jornal Zero Hora, evidenciou que um menino, no período com cinco anos de idade, presente em uma imagem, era filho de habitantes da colônia e, assim como os outros, estava com seu taco para jogar Gateball. Na reportagem, mencionava que ele a havia instruído sobre a maneira correta de utilizar o taco. A presença do garoto, na referida imagem, ainda que sugira um caráter mais recreativo, expõe a tentativa de continuação desta prática, a ser transmitida pelos mais velhos aos mais jovens.

O jogo de Gateball, por apresentar como atributos a lentidão dos movimentos e a curta duração das partidas, admite a existência de um amplo número de praticantes da terceira idade, alguns quase centenários. Da mesma forma, seu potencial para promover a integração é expressivo. "O real objetivo do jogo é manter a saúde e consolidar amizades" (ALVES FILHO, 2006). O jornal Zero Hora retratou o envolvimento de uma das residentes da colônia,

\footnotetext{
${ }^{10}$ Outras comunidades de nipo-brasileiros, como a Colônia Japonesa de Itapuã, no Rio Grande do Sul, também têm cultivado a prática do Gateball nos últimos anos, em grande parte por idosos que se reúnem na Associação ASERJI. Os encontros ocorrem, de forma mais frequente, em períodos que antecedem competições estaduais e interestaduais.
} 
Yasue Ozaki como uma atleta. Na reportagem, intitulada "Os jogos que unem a comunidade", a senhora de 71 anos, é citada como uma das praticantes de Gateball. O esporte representava quase uma unanimidade entre os nipo-brasileiros de Ivoti, que se agrupavam cerca de três vezes por semana para "dar umas tacadas" (OS JOGOS..., 16 jun. 2008, p.33).

Em meio a este divertimento, homens, mulheres e crianças encontravam espaço, depois das partidas, para deleitar-se com chá e acompanhamentos. Nestes intervalos, sentavam-se à sombra para uma merenda breve contendo manjus (doce com recheio de feijão), frutas e o clássico chá verde. O jogo ainda oportunizava a convivência e um espaço de conversa para se "contar as novidades". O assunto, comumente, eram os filhos que viviam longe (OS JOGOS..., 16 jun. 2008, p.33).

Cabe destacar que o Gateball parece ter sido uma prática que encontrou certa constância. Nas reportagens do jornal O Diário da Encosta da Serra, pertencente às tiragens do ano de 2014, foi evidenciado que, alguns dos moradores da colônia japonesa praticavam o Gateball ou, como é chamado popularmente entre eles, o "getoboru". O grupo de terceira idade havia aproveitado um domingo de páscoa para jogar, seguindo o costume dos habitantes, já que o jogo acontecia, normalmente, nas quartas-feiras, sábados e domingos na quadra da ACENB. Ao serem interrogados sobre a prática, afirmaram que o esporte era muito bom porque não demandava esforço físico; porém, exercitava o corpo e a mente dos participantes. Para jogar, também eram importantes concentração e estratégia.

No período em questão, no Brasil, ocorreram vários campeonatos do esporte. O campeonato nacional acontecia em São Paulo, tradicionalmente, no mês de abril, congregando, aproximadamente, 70 times, exclusivamente com participantes idosos. Os residentes da Colônia Japonesa, afora participarem do nacional, disputavam torneios regionais ao longo do ano todo, sendo que as categorias possuíam uma divisão conforme as idades dos integrantes. Conforme o descrito, existia a categoria Ouro, que compreendia participantes com mais de 70 anos; a Diamante, sendo necessário ter mais de 60 anos e menos de 70; e a Prata, que abrangia todos os participantes com menos de 60 anos (JAPONESES..., 23 abr. 2014, p. 25). 


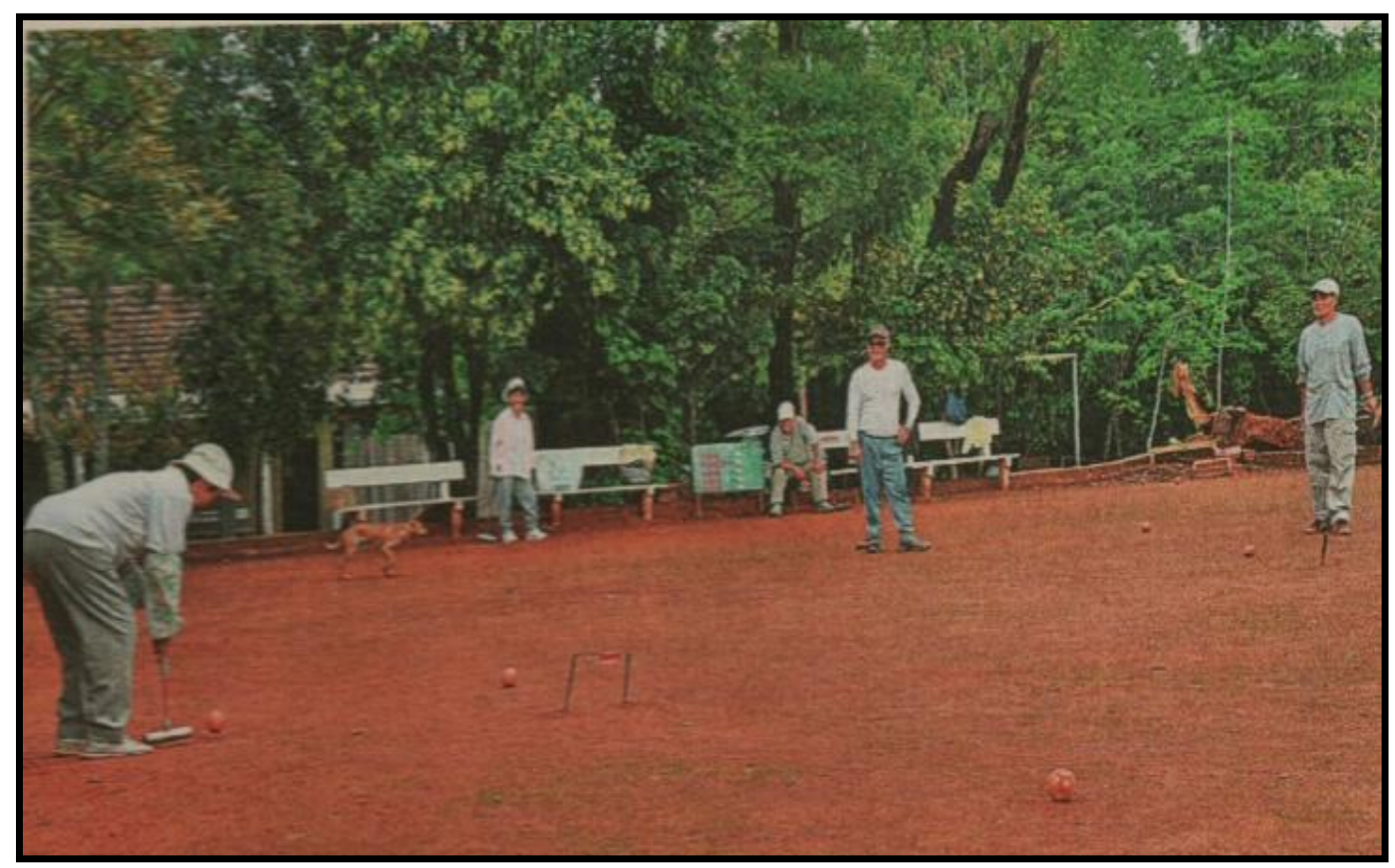

Imagem 1 - Idosos praticando Gateball em Ivoti. Fonte: JAPONESES..., 23 abr. 2014, p. 25.

Na imagem acima está representada parte dos materiais do jogo. Observa-se uma quadra de terra batida circundada por bancos e bem próxima a árvores e residências. Um(a) praticante está com o corpo inclinado, segurando um taco com o qual vai golpear a bola de sua ordem de jogo a fim de que esta ultrapasse o gate para, assim, pontuar. Percebe-se que quatro, dos cinco sujeitos presentes na imagem estão uniformizados, visto que, aparentemente estão identificados(as) em duas equipes, diferenciadas pelas cores das roupas - semelhantes para cada equipe. Provavelmente, estavam em um momento mais descontraído, visto que pareciam não se importar com a presença de um cão que cruzava a quadra, tampouco com o fato de serem fotografados.

É plausível inferir que a promoção do Gateball na comunidade, ao ser realizada na quadra da ACENB, ao longo de décadas, representa um importante elemento de fortalecimento da identidade japonesa. Ao considerar-se que o envolvimento de indivíduos, em uma prática presente em um determinado grupo, os leva a compartilhar sentimentos e valores em comum, a relação dos nipo-brasileiros com o Gateball sugere uma valorização das circunscrições culturais legadas dos primeiros imigrantes que chegaram a Ivoti/RS. Traços estes que mostraram vir seguidos de outras práticas, como, por exemplo, aquelas vinculadas à culinária típica presente nos momentos de intervalo. Outro tema compreendido foi a assimilação das noções do jogo por parte da criança que, entre os idosos, já mostrava "como fazer". 
Conforme elementos disponíveis em uma matéria de 1995, publicada no Jornal Livre Expressão, a ACENB, desde a ocasião de seu planejamento, compôs um cerne de integração para a comunidade. A associação conservava um edifício anexo, onde se localizava um gabinete odontológico, sala para atendimento médico, biblioteca e salas de aula para o estudo da língua japonesa. A associação proporcionava, também, uma academia para o exercício e prática de judô, além de possuir um local destinado a apresentações culturais e festejos. No mesmo local, localizava-se, ainda, uma cancha de Gateball que, na década de 1990, era praticado, sobretudo, aos domingos à tarde, contando com a participação dos idosos da comunidade, que ali se encontravam para seu lazer e entretenimento, integrando-se com as gerações mais novas. Um residente da colônia, Kuniharu Orita, que foi entrevistado por este jornal, apontou o quão avaliava importante esta integração e relação, pois, presenciava episódios em que as pessoas de idade encontravam-se esquecidas por suas famílias, "geralmente discriminadas, ao ponto de se acharem inválidas, às vezes se embebedando nos balcões dos bares" (COLÔNIA JAPONESA, 17 jan. 1995, p. 9).

Em um dos banners de exposição, exibidos no Memorial da Colônia Japonesa, encontram-se os subsídios abaixo, que corroboram as práticas mencionadas acima. Além destas, havia outras que também compõem parte do costume da comunidade:

A colônia japonesa sempre foi culturalmente muito ativa. Para os jovens que completam 20 anos, também sempre é feita uma comemoração, registrando a passagem da adolescência para a vida adulta. Há, no grupo, praticantes de Gateball e Softball ${ }^{11}$. Há, ainda, a preocupação em preservar a técnica do origami, dobradura com papel (SOCIAL..., 2016).

Ao analisar os eventos promovidos no município de Ivoti/RS, Dhein (2012, p. 618) relata que "é perceptível a preocupação com a preservação e a valorização da cultura, dos costumes e das tradições deixadas pelos antepassados”. A autora ressalta, também, que é comum a organização de encontros entre as Colônias Japonesas dos municípios vizinhos com o intuito de integrá-las e mantê-las vivas culturalmente. Vale a ressalva de que foram identificados materiais esportivos, doados pelas famílias de origem japonesa residentes na colônia, como raquetes decoradas chamadas Hagoita, igualmente exibidos em mostruário do Memorial da Colônia de Ivoti. Estas raquetes eram usadas em uma prática recreativa corriqueira entre os japoneses, o Hanetsuki que, análogo ao badminton, era realizado, normalmente, na passagem do ano novo. Foram localizados também materiais de Softball, como tacos, luvas e bolas.

${ }^{11}$ O Softball é um esporte semelhante ao Baseball, havendo poucas diferenças nas regras e, sendo praticado no Brasil, predominantemente, por mulheres (Cantarino Filho; Miura, 2010). 
No que acena aos subsídios apresentados pelos imigrantes japoneses, afora as artes marciais, estes abarcam práticas popularmente reconhecidas entre os descendentes e que, ainda hoje, são identificadas como "esporte de japonês". Este é o caso da prática do baseball que, apesar de ter chegado ao Brasil aproximadamente em 1901, por intercessão dos estadunidenses, tem sua prática continuada, no Rio Grande do Sul e no Brasil, em função dos nipo-brasileiros (SUZUKI; MIRANDA, 2008). O Gateball, de tal modo, obtém um contingente maior de praticantes idosos nas colônias do país (SUZUKI; MIRANDA, 2008; SILVA, 2012). Resgatam-se, assim, sentidos de permanência conferidos à prática do Gateball, manifestos em palavras, discursos, imagens e objetos vinculados ao seu contexto.

\section{Considerações Finais}

Este estudo buscou apresentar indícios de como transcorreu a prática corporal do Gateball na Colônia Japonesa de Ivoti, no Rio Grande do Sul, entre as décadas de 1980 e 2010. Para tanto, sublinhamos que, ao longo do tempo, os sujeitos constituem representações, traduzindo-as por meio de manifestações verbais, de registros documentais e de práticas culturais, tais como o Gateball. Este, por sua vez, se constitui enquanto prática que compõe a construção da identidade dos imigrantes japoneses e seus descendentes, atrelando-se, consequentemente, à conservação da memória cultural nipo-brasileira.

A partir da realização do estudo, foi possível evidenciar que as práticas corporais ligadas aos nipo-brasileiros transcendem as artes marciais, as quais, comumente, aparecem como os esportes de maior representatividade em termos da cultura japonesa. Assim, o Gateball, introduzido no Brasil por imigrantes japoneses a partir da década de 1970, compreende uma das práticas corporais que atravessam a constituição das comunidades nipobrasileiras, contribuindo para a preservação e a renegociação de tais práticas ao longo dos anos.

A ENKYOSUL e a ACENB, fundadas em 1969 e 1981, respectivamente, representam entidades de expressiva relevância na configuração do Gateball no Rio Grande do Sul, uma vez que atuaram na introdução da prática, bem como na promoção de encontros entre nipobrasileiros de diversas localidades do estado, particularmente, das colônias de Ivoti, Itapuã e Itati. Tais ocasiões, embora motivadas pelas partidas de Gateball, carregavam consigo a representação de diferentes significados. Assim, paralelamente à prática corporal do Gateball, eram compartilhados elementos culturais por intermédio da culinária, do artesanato e da 
língua japonesa, evidenciando a intencionalidade de fortalecimento da identidade nipônica no estado.

No contexto sul-rio-grandense, ao ser desenvolvido entre os nipo-brasileiros, a prática parece ter maior proximidade com os idosos da comunidade, que se encontravam na quadra da ACENB para, durante as partidas de Gateball, desfrutarem de lazer e diversão. Paralelamente a estes propósitos, o caráter competitivo fez-se presente ao refletir-se em campeonatos regionais e estaduais. A presença de crianças, mesmo que evidenciada em menor escala, sugere a tentativa de continuidade desta prática, a ser transmitida pelos mais velhos aos mais jovens.

\section{Referências bibliográficas}

ALMEIDA, Thais Rodrigues de. Gateball: jogo, cultura e identidade nipônica no Parque Farroupilha. Salão de iniciação Científica. Livro de resumos. Porto Alegre: UFRGS, 2003, p. 665.

ALVES, Alessandra; POCAIA, Alessandra. Que tal uma partida de gateball? Esporte japonês abre espaço para atletas de todas as idades. Revista na Esportiva, Santo Amaro, n.1, p.11-12, dez. 2005.

ALVES FILHO, Francisco. O ritmo lento do Gateball. Revista ISTOÉ, 19 de junho de 2006. Sessão Comportamento, edição $\mathrm{n}^{\mathrm{o}}$ 1917. Disponível em: http://istoe.com.br/6955_O+RITMO+LENTO+DO+GATEBALL/. Acesso em 02 de janeiro de 2017.

ASSMANN, Alice Beatriz. O associativismo esportivo em Santa Cruz do Sul/ Rio Grande do Sul: configurações de praticas culturais (da década de 1880 à década de 1910). Dissertação (Mestrado em Ciências do Movimento Humano), Universidade Federal do Rio Grande do Sul. Porto Alegre, 2015.

ASSMANN, Alice Beatriz. Figurações do Turnen no Sul do Brasil: redes de interdependência em escolas e clubes (décadas 1870-1920). Tese (Doutorado em Ciências do Movimento Humano) - Universidade Federal do Rio Grande do Sul. Porto Alegre, 2019.

Associação Cultural e Esportiva Nipo-Brasileira de Ivoti. Cartaz de divulgação do Memorial da Colônia Japonesa em 2016. Acervo pessoal Josiana Ayala Ledur.

BURKE, Peter. O que é História Cultural. Rio de Janeiro: Jorge Zahar, 2008. 216 p.

CANDAU, Joël. Memória e identidade. São Paulo: Contexto, 2012. 219p.

CANTARINO FILHO, Mario Ribeiro; MIURA, Hiromi. Japão e Brasília: imigração e esporte. Brasília: Thesaurus, 2010. 346 p.

CHARTIER, Roger. A história cultural: entre práticas e representações. Rio de Janeiro: Bertrand Brasil,1990. 244p.

COLÔNIA JAPONESA. Jornal Livre Expressão, Ivoti, p.A-9, 17 jan.1995. Recuperado em Acervo da Biblioteca Pública Municipal Laís Helena Bruck Mundstock da cidade de Ivoti.

COLÔNIA JAPONESA: gateball. Jornal Livre Expressão, Ivoti, p.A-8, $1^{\circ}$ Mai.1996. Recuperado em Acervo da Biblioteca Pública Municipal Laís Helena Bruck Mundstock da cidade de Ivoti. 
DHEIN, Cíntia Elisa. A interpretação patrimonial da imigração alemã para o turismo na Rota Romântica RS/BR. 2012. 176f. Dissertação (Mestrado em Turismo) - Universidade de Caxias do Sul, Caxias, 2012.

DILLY, Gabriela; GEVEHR, Daniel Luciano. Para não espetacularizar o passado: memória, identidade étnica e educação patrimonial na construção do Memorial da Colônia Japonesa de Ivoti. COLÓQUIO - Revista do Desenvolvimento Regional - Faccat - Taquara/RS - v. 11, n. 2, p. 55-70, jul./dez. 2014.

EMPRESAS DO BRASIL. Cadastro nacional. ACEI, 2015. Disponível em: $<$ http://empresasdobrasil.com/empresa/acei-90938259000170>. Acesso em 13 de novembro de 2016.

ASERJI, 2015. Disponível em: <empresasdobrasil.com/.../assoc-esportiva-rec-coloniajaponesa-itapua-aserji- 92099134000120>. Acesso em 13 de novembro de 2016.

ENKYOSUL. Jornal da Associação de Assistência Nipo e Brasileira do Sul, abr. 2012, capa. Encontrado no acervo da Associação de Assistência Nipo e Brasileira do Sul.

FROSI, Tiago; MAZO, Janice Zarpellon. O abrasileiramento do clube de remo dos italianos em Porto Alegre nas décadas de 1930-1940. Movimento, Porto Alegre. v. 18, n. 3, p. 51-71, jul./set. 2012.

GATEBALL foi bem representado nas homenagens do dia do Esportista em Caraguá. Expressão Caiçara: o Jornal do Litoral Norte, São Paulo, p. 7, 25 a 31 dez. 2013.

GAUDIOSO, Tomoko Kimura. O trabalho temporário no Japão e seu reflexo na estrutura familiar da colônia de Ivoti. In: IX Reunião de Antropologia do Mercosul- Curitiba, 2011.

IWASAKI, Jaqueline Morais. Diário de Ivoti: Mais gateball. CLICRBS, 18 mai. 2008. Disponível em: http://zerohora.clicrbs.com.br. Acessado em: 29 out. 2016.

IZUMI, Patrícia Tamiko. Envelhecimento e etnicidade: o processo de aculturação dos imigrantes japoneses. Dissertação (Mestrado em Letras) - Faculdade de Filosofia, Letras e Ciências Humanas da Universidade de São Paulo, São Paulo. Brasil, 2010.

JAPONESES PRATICARAM GATEBALL EM IVOTI. O Diário da Encosta da Serra, p.A25, 23 de abr. 2014. Recuperado em Acervo da Biblioteca Pública Municipal Laís Helena Bruck Mundstock da cidade de Ivoti.

KANAMOTO, Etsuko. Oi no bunka jinruigaku 1: oi no esunishiti - tabunka shakai nimiru nihon imin no rôgô. (Antropologia cultural da velhice 1: etnicidade da velhice - a velhice na imigração japonesa na visão da sociedade multicultural). Shôsai no mado, Tokyo: Yuhikaku, n. 566, p. 7-8, ago. 2007.

KANASHIRO, Miriam Masako; YASSUDA, Monica Sanches. Estudo da Adaptação e Aplicabilidade do Questionário Perfil de Atividades de Adelaide em Idosos de uma Comunidade Nipo-brasileira. Psicologia: Reflexão e Crítica, Porto Alegre, v. 24, n. 2, p. 245 253, 2011.

LEDUR, Josiana Ayala. Práticas corporais na colônia japonesa de Ivoti, Rio Grande do Sul (década de 1980 à década de 2010). Dissertação (Mestrado em Ciências do Movimento Humano) - Universidade Federal do Rio Grande do Sul. Porto Alegre, 2017.

MACHADO, André Roberto de Arruda. Entre o nacional e o regional: uma reflexão sobre a importância dos recortes espaciais na pesquisa e no ensino da História. Anos 90, Porto Alegre, v. 24, n. 45 , p. 293-319, 2017.

MAZO, Janice Zarpellon, et al. Danças tradicionais japonesas e representações sociais no sul do Brasil. In: Missias-Moreira, Ramon; Freitas, Vera Lúcia Chalegre De; Collares-Da-Rocha, Julio Cesar Cruz (Orgs.). Representações sociais na contemporaneidade. Curitiba: CRV, 2019, p. 121-137.

OS JOGOS QUE UNEM A COMUNIDADE. Jornal Zero Hora, p. A-33, 16 jun.2008.

PEREIRA, Ester Liberato. Configurações sociohistóricas da equitação no Rio Grande do Sul: uma investigação das redes de interdependência nas práticas esportivas equestres. Tese 
(Doutorado em Ciências do Movimento Humano) - Universidade Federal do Rio Grande do Sul. Porto Alegre, 2016.

PESAVENTO, Sandra Jatahy. Cultura e Representações, uma trajetória. Anos 90, v. 13, n. 23/24, p. 45-58, 2006.

PESAVENTO, Sandra Jatahy. História \& História Cultural. Belo Horizonte: Autêntica, 2008. 132 p.

PIMENTEL, Alessandra. O método da análise documental: seu uso numa pesquisa historiográfica. Cadernos de Pesquisa, São Paulo, n. 114, p. 179-195, nov. 2001. Disponível em: http://www.scielo.br/pdf/cp/n114/a08n114.pdf>. Acesso em: 13 jun. 2016.

SILVA, Bruno. Gateball. Neste domingo, Cascavel sediará o $134^{\circ}$ Campeonato do oeste do Paraná. Hoje News, Cascavel, p. A-18, $1^{\circ}$ jul. 2012.

SILVA, Carolina Fernandes da. Esportes náuticos e aquáticos no Rio Grande do Sul, Brasil: esportivização e contatos culturais nos clubes. Tese (Doutorado em Ciências do Movimento Humano) - Universidade Federal do Rio Grande do Sul. Porto Alegre, 2015.

SILVA, Carolina Fernandes da. O remo e a história de Porto Alegre, Rio Grande do Sul: mosaico de identidades culturais no longo século XIX. Dissertação (Mestrado em Ciências do Movimento Humano) - Universidade Federal do Rio Grande do Sul. Porto Alegre, 2011.

SOCIAL E ESPORTE. Banner de divulgação do Memorial da Colônia Japonesa de Ivoti, 2016. Acervo pessoal Josiana Ayala Ledur.

SUZUKI, Frank. Shiguemtsu Suzuki; MIRANDA, Maria Luiza de Jesus. A história da imigração japonesa e seus descendentes: prática de atividade física e aspectos sócio-culturais. Conexões: Revista da Faculdade de Educação Física da Unicamp, São Paulo, v.6 (ed. especial), p.409-418, jul. 2008.

TRAPHAGAN, John. W. Reasons for gateball participation among older Japanese. Journal of Cross-Cultural Gerontology, v.13, p.159-175, feb.1998.

REGIONAIS. UCGB. União dos Clubes de Gateball do Brasil, 5 out. 2015 - Disponível em: https://gateball.org.br/regionais/. Acesso em 15 fev. 2016.

UEMURA, Karoline Kika. Antes que as flores caiam: memórias e vivências acerca das migrações entre o Núcleo Celso Ramos (SC) e o Japão (1989-2010). Dissertação (Mestrado em História) - Universidade do Estado de Santa Catarina. Florianópolis, 2013.

VELOSO, Camila Motomatsu. Percepção de idosos praticantes de Gateball sobre a prática de atividade física. Trabalho de Conclusão de Curso - Departamento de Educação Física da Universidade Estadual de Londrina. Londrina, 2010. 